\title{
Dyslipidemia, Diabetes, and the Heart
}

\author{
Helmut Schatz \\ Ruhr-University, Bochum, Germany
}

\section{Article Info}

*Corresponding author:
Helmut Schatz
Ruhr-University
Bochum
Germany
E-mail: helmut.schatz@ruhr-uni-bochum.de

Received: September 27, 2016

Accepted: November 2, 2016

Published: November 7, 2016

Citation: Schatz H. Dyslipidemia, Diabetes, and the Heart. Madridge J Diabetes. 2016; 1(1): 29-30.

doi: $10.18689 / \mathrm{mjd}-1000105$

Copyright: (c) 2016 The Author(s). This work is licensed under a Creative Commons Attribution 4.0 International License, which permits unrestricted use, distribution, and reproduction in any medium, provided the original work is properly cited.

Published by Madridge Publishers

\section{Introduction}

During the European Congress of Cardiology in Rome, August 2016, the Joint Guidelines of this Association together with the European Atherosclerosis Society about the "Management of Dyslipidemias" has been published. In this mini-review the relevant points for "Diabetes and Cardiovascular (CV) Risk" shall be discussed.

First, "CV Risk Factors" have to be considered. A very high risk factor is, besides documented CV disease and severe chronic kidney disease (CKD), diabetes mellitus with target organ damage. The other diabetic patients are at high risk, in addition to subjects having cholesterol levels $>8 \mathrm{mmol} / \mathrm{L} />310 \mathrm{ng} / \mathrm{dl}$ or a blood pressure $>/=180 / 110 \mathrm{~mm}$ $\mathrm{Hg}$. Young type-1-diabetes patients without major risk factors, however, may be at low or moderate risk.

Second, a CV Risk Score for the 10-year risk of fatal CV disease (CVD) has to be calculated specifically for different countries. The CV risk score depends from gender, smoking, age, total cholesterol and systolic blood pressure as well as from the country epidemiologic data concerning CV mortality. E.g. Algeria, Belarus, Egypt, Russia and Ukraine belong to a group of countries with a very high risk, in contrast to low risk countries located in western, northern or central parts of Europe.

Risk Factor screening has to be considered in men $>40 \mathrm{ys}$ and women $>50 \mathrm{ys}$ or postmenopausal. The Risk Score can assist in decisions, avoiding both under- and overtreatment. People at high or very high CV risk do not need risk scoring: They require immediate attention to all risk factors. This category includes patients with documented CVD, diabetes or chronic kidney disease.

\section{Diagnosis}

LDL-Cholesterol is the primary lipid parameter that should be assessed, Total Cholesterol is usually not sufficient for the characterization of untreated dyslipidemia. HDL-Cholesterol may also be estimated before treatment. Triglycerides add information about the risk level, and their measurement is indicated for diagnosis and choice of treatment. Lipoprotein(a) may be determined in selected cases at high risk.

\section{Pharmacologic treatment of hypercholesterolaemia}

Prescribe a statin up to the highest recommended or tolerable dose to reach the goal.

Statin intolerance: etzetimibe or a bile acid sequestrant, or both

Goal not reached: statin combination with a cholesterol absorption inhibitor or a bile acid sequestrant. In selected cases: a PCSK9 inhibitor 


\section{Treatment goals}

In T1D with renal involvement: LDL-lowering (at least $50 \%$ ) with statins irrespective of the baseline LDL-concentration

In T2D with CVD or CKD or $>40 \mathrm{ys}: \mathrm{LDL}<1.8 \mathrm{mmol} / \mathrm{L} /<70$ $\mathrm{mg} / \mathrm{dL}$

In all patients with T2D without additional risk factor LDL $<2.6 \mathrm{mmol} / \mathrm{l} /<100 \mathrm{mg} / \mathrm{dL}$.

This is in contrast to the US. In Europe it is recommended to "Treat to Target" and not "Fire and Forget".

"RULE of 6": Each doubling of the statin dose leads to a 6\% LDL-cholesterol-lowering only

Do not drink grapefruit juice. It interacts with statins metabolized by CYP3A4 leading to increased risk of myopathy and rhabdomyolysis.

\section{And do not forget life style!}

Conflicts of Interest: The author reports no conflict of interest.

\section{Literature}

Committee for Practice Guidelines to improve the quality of clinical practice and patient care in Europe: Dyslipidaemias. Rome, August 2016. www.escardio.org/guidelines 